\section{The Rise of Foundations \\ Hope for Grassroots Civil Society in China?}

\section{Jessica C. Teets}

Over the past decade, the not-for-profit foundation sector has grown rapidly in China. This expansion has occurred as international foundations and organisations were withdrawing funding from Chinese grassroots NGOs, causing many civil society leaders to put their hopes into domestic foundations as a way to close their deficit of funding. But can the rise of foundations in China really replace the evaporating foreign grants for domestic NGOs?
After the new Regulations on Administration of Foundations were promulgated by the Ministry of Civil Affairs in 2004, foundations (jijinhui)-that is not-for-profit organisations that promote public benefit undertakings through grants and donations-experienced rapid growth in China. In light of this, some observers considered private foundations to be the hope of China's third sector (China Development Brief 2011). The rapid expansion of the foundation sector indeed occurred as international foundations and organisations were withdrawing funding from Chinese grassroots NGOs, and many civil society leaders hoped that foundations would replace the international funding deficit. According to a report by the China Development Brief, 'NGOs cannot rely solely on international foundations. In the future, international foundations will move on to other countries. Even now you see international foundations will not use the majority of their funding on a country like China that is developing so fast' (2011, 12). In fact, the Global Fund withdrew funding from China in 2013, the Ford Foundation changed its funding profile so that less than one third of its funding went to grassroots NGOs (Spires 2011), and the new Foreign NGOs Management Law

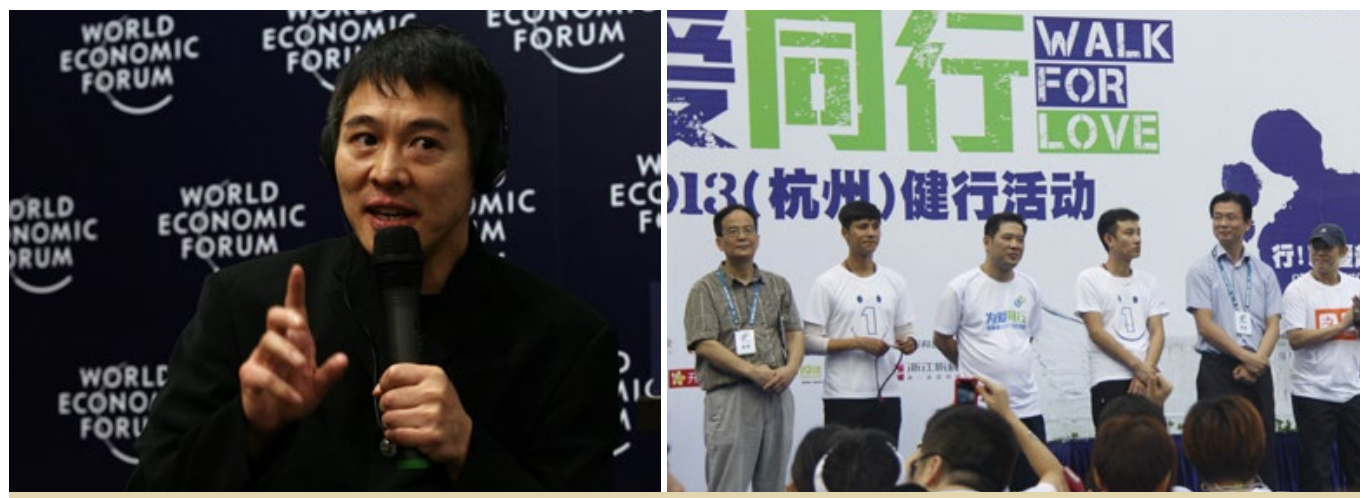

(Left) Jet Li, movie star and President of the One Foundation; (Right) Supporters of the One Foundation during a charity event. Photo: Wikimedia Commons; One Foundation. 
passed in 2016 restricts foreign funding of domestic social organisations (Hsu and Teets 2016; Franceschini and Nesossi 2017). In this essay, I explore whether the rise of foundations in China could serve as a potential funding source to replace foreign grants for domestic NGOs.

Despite the promise of the rise of Chinese foundations, I find that they function differently from their counterparts in the United States, in that very few foundations make grants to other nonprofit organisations. This might be a result of differences in the identity (or missions) of Chinese foundations, or simply due to their relatively early stage of development. Regardless of the reason, since foundations mostly finance their own projects rather than funding other organisations, they often compete with, rather than support, NGOs. If this trend continues after the implementation of the Foreign NGOs Management Law further restricts foreign funding, grassroots NGOs will depend entirely on private donations and government-awarded service contracts for funding. Government contracts do not help grassroots NGOs build capacity in the same way that grants often do, in that most contracts prohibit the use of funding for salaries or restrict other administrative costs to ten percent of the total value of the contract. In order to promote a more diverse and active civil society sector, foundations in China should partner more with grassroots NGOs to build civil-society capacity and replace lost international funding. For example, the Narada Foundation provided ten million yuan to NGOs for over sixtytwo projects related to disaster relief and to aid reconstruction after the 2008 Sichuan earthquake (China Development Brief 2011). This undoubtedly had a large impact on the groups receiving funding, and arguably helped them build capacity.

\section{The Rise of the Foundations Sector in China}

Although the first foundations were established in 1981, the rapid expansion of this sector did not occur until after the 2004 Regulations were passed, reducing capital barriers to two million yuan. The earliest were public foundations, mostly funded and managed by the government, and the 2004 Regulations distinguish between 'public fundraising foundations' (gongmu jijinhui) which are allowed to raise funds publicly, and non-public fundraising foundations (feigongmu jijinhui), which are not allowed to raise funds publicly. Before 2004, over eighty percent of all foundations were government-initiated public foundations; but after 2004, private foundations increased to forty percent (China Foundation Center 2013). Although private citizens started some of these private foundations, many are established by companies, especially those in real estate. In 2010, the number of private foundations overtook public ones, and by 2013 the total number of foundations reached 3,082-1,753 private and 1,329 public (Feng 2013). At the latest count, 5,209 foundations were registered in China (data from the China Foundation Center). Education is their most common focus, with fifty-three percent of all foundations focusing on education as a key area. By 2013 , there were 422 education foundations, with net assets, income and charitable spending accounting for nearly half of the total spending of private foundations (China Foundation Center 2013).

Why is the emergence of a foundation sector so important? According to Joel Fleishman (2007), in the United States, foundations represent 'the operational secret of America's civic sector' by playing 'the priming role ... in starting new civic- 

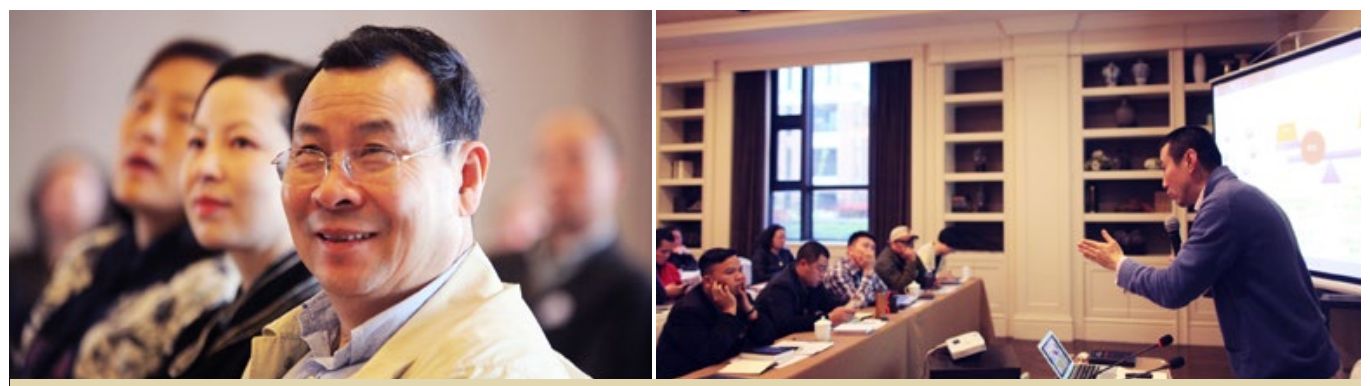

(Left) Xu Yongguang, President of the Narada Foundation and Emeritus Chairman of the China Foundation Center. (Right) Members of the Narada Foundation during a meeting. Photos: Narada Foundation.

sector organisations, they nurture them into self-sustainability, and provide a continuous supply of social venture capital to the civic sector.' While almost eighty percent of the foundations in the United States are grantmaking, private Chinese foundations mostly operate their own projects; one study found that only 1.6 percent of all public foundations and 13.2 percent of all private foundations could be categorised as grant-making (Kang et al. 2012). Thus, despite the promise of private foundations becoming "the hope of China's third sector', very few foundations currently make grants to other non-profit organisations: 43.5 percent provide some grants to grassroots organisations, but only nine percent are solely grant-making foundations (Feng 2015). As Xu Yongguang, the President of the Narada Foundation and Emeritus Chairman of the China Foundation Center, notes, private foundations that fund NGOs are still in the minority (China Development Brief 2011). This results in insufficient support for grassroots NGOs-a situation that will take time to change.

Despite its growing number of wealthy citizens, China has also been criticised for having little charitable giving. For example, the 2015 'World Giving Index' ranked China 144 out of 145. Furthermore, while many foundations have been established, indicating the potential for an expanded charity sector, the China Foundation Ranking-a survey of grassroots Chinese
NGOs that looks at their experiences with funders-criticised these organisations for not engaging in promoting the development of the sector or supporting the work of local NGOs. In the words of Chen Yimei, the Executive Director of the China Development Brief, '[the China Foundation Ranking] helps to make foundations realize that they should treat NGOs with more equality in their partnerships, rather than just assume a top-down relationship.... It's a critical moment, a time when foundations are thinking about their operating model and the philanthropy sector is contemplating whether we should have more grant-making foundations' (Bannister 2014).

\section{Sources of Change?}

The lack of NGO support on the part of Chinese foundations might be due to a number of reasons, including legal impediments, habits of donors and foundations, or just an early stage of development. For example, over 85 percent of foundations have been registered with low levels of initial capital, under eight million yuan (Kang et al. 2012). As regulations and habits change, will we see that more Chinese foundations assume a grant-making role, similar to the foundations in the United States? Or, as these foundations continue to develop, will we see persistence along a unique path of 
development, i.e. 'foundations with Chinese characteristics'?

Regarding legal impediments, there is a great deal of change in the regulations governing this sector. The 2004 Regulations promoted the expansion of the foundation sector due to changes in tax laws, as well as the formation of private foundations. More recently, the 2016 Foreign NGOs Law restricts the ability of international foundations to fund grassroots NGOs in China. This means that Chinese NGOs will need to depend more on domestic sources of funding. In addition to increasing services contracted by local governments, the 2016 Charity Law allows any registered charity to apply for permission to seek public donations (see also the chapter by Simon and Snape in the present volume). This major change might provide more funding sources for NGOs, in addition to funding from foundations which, Shawn Shieh notes, is slowly increasing through mechanisms like 'special funds' and 'joint fundraising' (2014). The regulations governing registration and management of the three types of 'social organisations' (shehui zuzhi) are currently under revision, and amendments are expected to be issued related to the Regulations on the Registration and Administration of Social Associations (1998); the Interim Regulations on the Registration and Administration of Civil Non-Enterprise Institutions (1998); and the Regulations on the Management of Foundations (2004) (Simon and Snape 2017).

In addition to legal changes that seem to encourage philanthropic giving and the expansion of the foundation sector, there is also a shift in habits of both donors and foundations regarding willingness to fund NGOs. This began in 2008 after the Sichuan earthquake. In 2016 the top one hundred Chinese philanthropists donated 37.9 billion yuan, up nearly twenty-five percent from the record 30.4 billion yuan given in 2014, underscoring the philanthropic potential in China (Simon and Snape 2017). Since, as $\mathrm{Xu}$ Yongguang notes, public foundations control most of the public donations in China, it may be more important to convince these types of foundations to support NGOs, as when the Chinese Red Cross offered funding to grassroots NGOs for the first time in the wake of the 2008 Sichuan earthquake (China Development Brief 2011). Xu and other foundation leaders are also creating initiatives like the China Private Foundation Forum and the China Foundation Center to encourage greater cooperation between foundations and NGOs.

These changes in the laws supporting foundations and philanthropy, shifting norms around charitable giving, coupled with the continued development of the foundation sector in China, might encourage foundations to take on more of a grant-making role similar to foundations in the United States. However, becoming a grant-maker is not inevitable, and is instead a decision that the founder must make. In this way, the unique path of development for Chinese foundations might influence whether foundations choose a grantmaking mission over a project-based one. As Shawn Shieh contends: 'In our interviews, a surprising number of foundations who did commit to grant-making did so either because their founders had participated in or were in some way influenced by international philanthropic approaches' (Shieh 2014). If the American model of grant-making influences the development of Chinese foundations, this would provide an invaluable source of funding for Chinese NGOs, especially as these grants might allow for a stronger focus on capacity building, unlike government service contracts. Although there remain many obstacles, the collaboration between an increasingly vigorous foundation sector and Chinese NGOs would thus end up reinforcing the continued development of each. 
This text is taken from Gilded Age: A Year of Chinese Labour, Civil Society, and Rights, Made in China Yearbook 2017, edited by Ivan Franceschini and Nicholas Loubere, published 2018 by ANU Press, The Australian National University, Canberra, Australia.

doi.org/10.22459/MIC.04.2018.20 